\title{
Homogenous nucleation of sulfuric acid and water at close to atmospherically relevant conditions
}

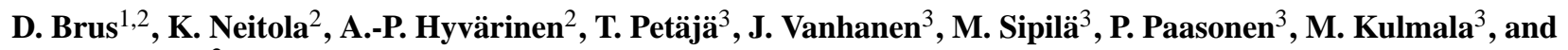 \\ H. Lihavainen ${ }^{2}$ \\ ${ }^{1}$ Laboratory of Aerosol Chemistry and Physics, Institute of Chemical Process Fundamentals Academy of Sciences of the \\ Czech Republic, Rozvojová 135, 16502 Prague 6, Czech Republic \\ ${ }^{2}$ Finnish Meteorological Institute, Erik Palménin aukio 1, P.O. Box 503, 00100 Helsinki, Finland \\ ${ }^{3}$ Department of Physics, University of Helsinki, P.O. Box 64, 00014 Helsinki, Finland
}

Received: 16 September 2010 - Published in Atmos. Chem. Phys. Discuss.: 3 November 2010

Revised: 10 May 2011 - Accepted: 30 May 2011 - Published: 6 June 2011

\begin{abstract}
In this study the homogeneous nucleation rates in the system of sulfuric acid and water were measured by using a flow tube technique. The goal was to directly compare particle formation rates obtained from atmospheric measurements with nucleation rates of freshly nucleated particles measured with particle size magnifier (PSM) which has detection efficiency of unity for particles having mobility diameter of $1.5 \mathrm{~nm}$. The gas phase sulfuric acid concentration in this study was measured with the chemical ionization mass spectrometer (CIMS), commonly used in field measurements. The wall losses of sulfuric acid were estimated from measured concentration profiles along the flow tube. The initial concentrations of sulfuric acid estimated from loss measurements ranged from $10^{8}$ to $3 \times 10^{9}$ molecules $\mathrm{cm}^{-3}$. The nucleation rates obtained in this study cover about three orders of magnitude from $10^{-1}$ to $10^{2} \mathrm{~cm}^{-3} \mathrm{~s}^{-1}$ for commercial ultrafine condensation particle counter (UCPC) TSI model $3025 \mathrm{~A}$ and from $10^{1}$ to $10^{4} \mathrm{~cm}^{-3} \mathrm{~s}^{-1}$ for PSM. The nucleation rates and the slopes $\left(d \ln J / d \ln \left[\mathrm{H}_{2} \mathrm{SO}_{4}\right]\right)$ show satisfactory agreement when compared to empirical kinetic and activation models and the latest atmospheric nucleation data. To the best of our knowledge, this is the first experimental work providing temperature dependent nucleation rate measurements using a high efficiency particle counter with a cutoff-size of $1.5 \mathrm{~nm}$ together with direct measurements of gas phase sulfuric acid concentration.
\end{abstract}

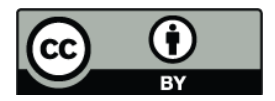

Correspondence to: D. Brus (brus@icpf.cas.cz)

\section{Introduction}

Atmospheric new particle formation consists of rather complicated sets of processes, the first of them is gas-to-particle nucleation. It is generally accepted that sulfuric acid is a robust source of new particles and plays a central role in atmospheric new particle formation (Weber et al., 1996, 1997; Kulmala, 2003). In number of field experiments (e.g. Weber et al., 1996; Sihto et al., 2006; Riipinen et al., 2007; Zhao et al., 2010) and also in some laboratory studies (e.g. Berndt et al., 2005, 2010, Young et al., 2008, Sipilä et al., 2010) the rate of particle formation is not adequately explained by binary classical homogenous nucleation (CNT), the theory greatly under predicts the observed nucleation. According to Kashchiev (1982) the relationship (the slope, $d \ln J / d \ln$ $\left[\mathrm{H}_{2} \mathrm{SO}_{4}\right]$ ) between particle production rate and sulfuric acid concentration directly corresponds to number of molecules in critical cluster. In atmospheric measurements and also in a laboratory studies (Sipilä et al., 2010; Berndt et al., 2010) it was observed that particle number concentration followed a power-law dependency of about 1-2, compared to CNT prediction that suggest exponents from 4 to 9 (Vehkamäki et al., 2002). This discrepancy has been puzzling to atmospheric researchers for more than a decade. As a solution to this problem it has been suggested that other associate molecule as ammonia and amines (Weber et al., 1996; Berndt et al., 2010) or organic acids (Zhang, 2010; Zhang et al., 2004; Metzger et al., 2010; Paasonen et al., 2010) may have a stabilizing effect on the clusters and allow nucleation to occur at much lower concentrations of sulfuric acid than needed by CNT. The first in-situ atmospheric measurements of sulfuric acid in troposphere by using chemical ionization mass spectrometer

Published by Copernicus Publications on behalf of the European Geosciences Union. 
(CIMS) were reported by Eisele and Tanner (1993). Since that time CIMS was used in many field studies in diverse locations around the world (e.g. Weber et al., 1996, 1997; Mauldin et al., 1998; Sihto et al., 2006; Riipinen et al., 2007; Petäjä et al., 2009, Zhao et al., 2010) and also in laboratory studies (e.g. Ball et al., 1999; Zhang et al., 2004; Benson et al., 2008; Young et al., 2008; Sipilä et al., 2010).

Compared to our previous study (Brus et al., 2010) we apply here a similar approach as is commonly used in atmospheric measurements. The gas phase sulfuric acid concentration was measured with the chemical ionization mass spectrometer (CIMS). The number concentration of freshly nucleated particles was measured in parallel with commercial UCPC TSI 3025A and particle size magnifier (PSM) with particle counting efficiency close to unity for particles of $\sim 1.5 \mathrm{~nm}$, (Vanhanen et al., 2011).

\section{Experimental setup}

The same experimental setup as introduced in Brus et al. (2010) was used in this investigation. The experimental setup details and the principle of operation can be found therein. Only brief description of apparatus, its principle of operation and differences associated with particle counting and determination of sulfuric acid concentration are discussed here. The experimental setup consists of five main parts: an atomizer, a furnace, a mixing unit, a nucleation chamber and a particle detector unit. A liquid solution of known concentration and amount $\left(0.22 \mathrm{ml} \mathrm{min}^{-1}\right)$ is introduced by the HPLC Pump (Waters 515) through a ruby micro-orifice (Bird Precision - $20 \mu \mathrm{m}$ ) together with particle free air (about $41 \mathrm{~min}^{-1}$ ) into the furnace. The dispersion is vaporized in a furnace (Pyrex glass tube) which is $60 \mathrm{~cm}$ long and has an internal diameter (I.D.) of $2.5 \mathrm{~cm}$. The tube is wrapped with resistance heating wires. The temperature inside the furnace is kept at approximately $470 \mathrm{~K}$ and controlled by a PID controller to within $\pm 0.1 \mathrm{~K}$ (DigiTrace, TCONTROL-CONT-02). After the furnace, the vapor is filtered with a Teflon filter (MITEX ${ }^{\mathrm{TM}}$ Millipore $5.0 \mu \mathrm{m}$ LS) to remove any liquid residue or particulate impurities. The Teflon filter is placed on the perforated Teflon support pad just after the furnace, and before the entrance to the mixing unit. The filtered vapor is then introduced into the mixing unit, made of Teflon, and cooled by turbulent mixing with room temperature particle free air to about $320 \mathrm{~K}$. The flow rate of the mixing air is about $81 \mathrm{~min}^{-1}$. The mixing unit dimensions are: O.D. $=10 \mathrm{~cm}$, I.D. $=7 \mathrm{~cm}$, height $=6 \mathrm{~cm}$. The mixing unit is kept at room temperature and it is not insulated. Both lines of particle free air are controlled by a flow rate controller to within $\pm 3 \%$ (MKS type 250 ). The vapor gas mixture is then cooled to the desired nucleation temperature in a nucleation chamber, which is kept at a constant temperature with two liquid circulating baths (Lauda RK20). The nucleation chamber is made of stainless steel, with an I.D. of $6 \mathrm{~cm}$ and an entire length of $200 \mathrm{~cm}$. The concentration of water vapor is measured at the middle and far end of the nucleation chamber with two humidity and temperature probes (Vaisala HMP37E and humidity data processor Vaisala HMI38) to within $\pm 3 \%$. The aerosol number concentration is measured just after the nucleation chamber with an ultrafine condensation particle counter (UCPC) TSI model 3025A and simultaneously with particle size magnifier (PSM). The sulfuric acid concentration is measured also at the end of the nucleation chamber with chemical ionization mass spectrometer (CIMS).

The liquid samples of sulfuric acid and water mixture are prepared from a $0.01 \mathrm{M}$ solution of $\mathrm{H}_{2} \mathrm{SO}_{4}$ (Reagecon, AVS purity) and ultrapure water (Millipore, TOC less than $10 \mathrm{ppb}$, resistivity $18.2 \mathrm{M} \Omega . \mathrm{cm} @ 25^{\circ} \mathrm{C}$ ). The desired solution concentration is prepared in two steps of dilution. First, 11 of primary solution of concentration $\left(1.96 \times 10^{-4} \mathrm{moll}^{-1}\right)$ is made by adding $20 \mathrm{ml}$ of $0.01 \mathrm{~mol} \mathrm{H}_{2} \mathrm{SO}_{4}$ to 11 of pure water. Then the desired final solution for a particular measurement is made. To cover RH's from $60 \%$ to $10 \%$ we prepare 11 of final solution from $0.5 \mathrm{ml}$ to $70 \mathrm{ml}$ of primary solution. The final solution concentration is always checked by Ion Chromatography with a lower detection limit of $0.02 \mathrm{mgl}^{-1}$ of $\mathrm{SO}_{4}^{2-}$ in the analytical laboratory at the Finnish Meteorological Institute.

\subsection{Chemical Ionization Mass Spectrometer, CIMS}

Sulfuric acid was measured with a chemical ionization mass spectrometer, CIMS (Eisele and Tanner, 1993; Mauldin et al., 1998; Petäjä et al., 2009). The sulfuric acid in the sample flow is chemically ionized by $\left(\mathrm{NO}_{3}^{-}\right)$ions. The reagent ions are generated by nitric acid and a $241 \mathrm{Am}$ alpha source and mixed in a controlled manner in a drift tube utilizing concentric sheath and sample flows together with electrostatic lenses.

Prior to entering the vacuum system, the chemically ionized sulfuric acid molecules pass through a layer of dry nitrogen flow in order to dehydrate the sulfuric acid. In the vacuum system the sulfuric acid clusters are dissociated to the core ions by collisions with the nitrogen gas seeping through the pinhole in the collision-dissociation chamber (Eisele and Tanner, 1993). The sample beam is collimated with a set of conical octopoles, mass filtered with a quadrupole and detected with a channeltron. The sulfuric acid concentration is determined by the ratio between the signals at $\mathrm{m} / \mathrm{z}$ channel of $97 \mathrm{Da}\left(\mathrm{HSO}_{4}^{-}\right)$and the reagent ion at $\mathrm{m} / \mathrm{z}$ channel of $62 \mathrm{Da}$ $\left(\mathrm{NO}_{3}^{-}\right)$multiplied by the instrument and setup dependent calibration factor.

The calibration factor is determined by photolyzing ambient water vapor with a mercury lamp to generate a known amount of $\mathrm{OH}$ radicals in front of the inlet. The produced $\mathrm{OH}$ radicals subsequently convert isotopically labeled ${ }^{34} \mathrm{SO}_{2}$ into labeled sulfuric acid in a well defined reaction time yielding finally after ionization $\left(\mathrm{H}^{34} \mathrm{SO}_{4}^{-}\right)$. A nominal detection 
Table 1. Sulfuric acid losses in the upper half of the nucleation chamber at three relative humidities, RH (16, 32 and $57 \%)$, $\mathrm{T}=25^{\circ} \mathrm{C}$, where $k_{\mathrm{obs}}$ is the observed loss rate coefficients, $v$ is mean flow velocity, $t$ is residence time, WLF is the wall loss factor, and $\mathrm{WLF}_{\text {inlet }}$ is the wall loss factor estimated for CIMS' inlet sampling tube.

\begin{tabular}{cccccc}
\hline $\begin{array}{c}\mathrm{RH} \\
{[\%]}\end{array}$ & $\begin{array}{c}k_{\mathrm{obs}} \\
{\left[\mathrm{cm}^{-1}\right]}\end{array}$ & $\begin{array}{c}v \\
{\left[\mathrm{~cm} . \mathrm{s}^{-1}\right]}\end{array}$ & $\begin{array}{c}t \\
{[\mathrm{~s}]}\end{array}$ & $\mathrm{WLF}$ & $\mathrm{WLF}_{\text {inlet }}$ \\
\hline 57 & -0.01 & 7.9 & 25.2 & 6.6 & 3.3 \\
32 & -0.0092 & 7.4 & 27.1 & 6.5 & 4.4 \\
16 & -0.0092 & 7.3 & 27.5 & 6.0 & 4.6 \\
\hline
\end{tabular}

limit of the CIMS instrument is $5 \times 10^{4}$ molecules $\mathrm{cm}^{-3}$ for a $5 \mathrm{~min}$ integration period. The error estimate in determined concentrations is estimated to be about factor of 2. CIMS was used also to detect sulfuric acid dimers. The calibration factor used for monomers was applied also in converting the dimer signal to concentration. Since the transmission for dimer $(\mathrm{m} / \mathrm{z}$ channel of $195 \mathrm{Da})$ can differ from monomer (97 Da), use of the single calibration factor causes error in the determined concentration. Furthermore, our reported dimer signal comprises dimers formed both via neutral processes inside the flow tube and dimers formed by ion induced mechanism in the CIMS charger, for detailed discussion see Petäjä et al. (2011). Therefore our results concerning the dimer concentrations are still somewhat qualitative.

\section{$2.2 \quad \mathrm{H}_{2} \mathrm{SO}_{4}$ losses}

Sulfuric acid wall losses were determined experimentally by measuring the losses of sulfuric acid concentration along the nucleation chamber. Two sets of experiments were conducted. First, relative humidity was changed (16, 32 and $57 \%)$ and nucleation temperature $\left(25^{\circ} \mathrm{C}\right)$ was kept constant. Second, nucleation temperature was changed $(25,15$ and $\left.5{ }^{\circ} \mathrm{C}\right)$ and relative humidity was kept constant $(\sim 50 \%)$. The nucleation chamber consists of two 1 meter long interchangeable parts; one of them is equipped with 4 holes in equal distance of $20 \mathrm{~cm}$ from beginning and from each other. In the first set of measurements the holes were in upper position so we measured sulfuric acid losses for relative humidities $16,32,57 \%$ in distances of $20,40,60$, and $80 \mathrm{~cm}$ from the beginning and then at the end $(200 \mathrm{~cm})$ of the nucleation chamber. The slopes obtained from the fits to experimental data $\ln \left(\left[\mathrm{H}_{2} \mathrm{SO}_{4}\right]\right)$ vs. distance in the nucleation chamber stand for the loss rate coefficient, $k_{\mathrm{obs}}\left(\mathrm{cm}^{-1}\right)$, under the assumption that the only sink for molecular sulfuric acid is the first order loss to the flow tube wall. To be able to measure along whole nucleation chamber an additional CIMS inlet sampling tube had to be used, which is a stainless steel tube with I.D. $10 \mathrm{~mm}$ and its whole length was $122 \mathrm{~cm}(100 \mathrm{~cm}$ straight $+22 \mathrm{~cm}$ elbow-pipe). The sulfuric
Table 2. Sulfuric acid losses in the lower half of the nucleation chamber at three temperatures, $T\left(25,15\right.$ and $\left.5^{\circ} \mathrm{C}\right), \mathrm{RH} \sim 50 \%$, where $k_{\text {obs }}$ is the observed loss rate coefficients, $v$ is mean flow velocity, $t$ is residence time, WLF is the wall loss factor, and WLF $\mathrm{Wnlet}_{\text {in }}$ is the wall loss factor estimated for CIMS' inlet sampling tube.

\begin{tabular}{lccccc}
\hline $\begin{array}{l}T \\
{\left[{ }^{\circ} \mathrm{C}\right]}\end{array}$ & $\begin{array}{c}k_{\mathrm{obs}} \\
{\left[\mathrm{cm}^{-1}\right]}\end{array}$ & $\begin{array}{c}v \\
{\left[\mathrm{~cm} \cdot \mathrm{s}^{-1}\right]}\end{array}$ & $\begin{array}{c}t \\
{[\mathrm{~s}]}\end{array}$ & WLF & WLF inlet \\
\hline 25 & -0.0063 & 7.7 & 25.3 & 3.6 & 3.9 \\
15 & -0.0069 & 7.2 & 27.6 & 4.0 & 4.4 \\
5 & -0.0072 & 7.2 & 27.6 & 4.2 & 6.8 \\
\hline
\end{tabular}

acid losses in the CIMS' inlet sampling tube itself were estimated in separate experiment by using two different lengths of straight sampling tube, 50 and $100 \mathrm{~cm}$. In Table 1 can be found the observed loss rate coefficients, $k_{\mathrm{obs}}$, mean flow velocity, $v$, residence time, $t$, the wall loss factor, WLF, and the wall loss factor estimated for CIMS' inlet sampling tube, $\mathrm{WLF}_{\text {inlet. }}$ The overall sulfuric acid losses in the nucleation tube and the inlet sampling tube are then $\mathrm{WLF} \times \mathrm{WLF}_{\text {inlet }}$. The initial sulfuric acid concentration $\left[\mathrm{H}_{2} \mathrm{SO}_{4}\right]_{\text {init }}$ is then obtained as $\left[\mathrm{H}_{2} \mathrm{SO}_{4}\right]_{\text {measured }} \times \mathrm{WLF} \times \mathrm{WLF}_{\text {inlet }}$. The wall loss factor (WLF) increases with relative humidity, which is due to presence of temperature gradient in first $50 \mathrm{~cm}$ in the nucleation chamber, see Brus et al. (2010) for details. The presence of temperature gradient (both axial and radial) imposes thermophoretic force towards the cooled nucleation chamber wall (set to $25^{\circ} \mathrm{C}$ ) and also increases the value of diffusion coefficient, thus increasing WLF in first $50 \mathrm{~cm}$. There is no temperature gradient in the CIMS' sampling tube and the $\mathrm{WLF}_{\text {inlet }}$ is behaving as expected, the $\mathrm{WLF}_{\text {inlet }}$ is increasing with decreasing RH, (Hanson and Eisele, 2000).

In the second set of loss measurements the positions of nucleation chamber parts were exchanged, so the holes were in lower part of nucleation chamber. This was done to ensure the reproducibility of experiment at relative humidity $\sim 50 \%$, and also find out how big role plays the axial temperature gradient (thermophoresis and higher diffusion coefficient) in first $50 \mathrm{~cm}$ of the nucleation chamber. The sulfuric acid losses were measured at three nucleation temperatures $\left(25,15\right.$ and $\left.5^{\circ} \mathrm{C}\right)$ and relative humidity $\sim 50 \%$ at distances of $120,140,160,180$, and $200 \mathrm{~cm}$. Table 2 contains the obtained loss rate coefficients together with accompanied parameters. The WLF is generally smaller then in the first set of experiment due to smaller and constant diffusion coefficient; i.e. there is no axial temperature gradient present in lower part of nucleation chamber. The WLF is increasing with decreasing nucleation temperature again due to increased radial temperature gradient. The $\mathrm{WLF}_{\text {inlet }}$ is even pronounced because the CIMS' sampling inlet tube was not temperature controlled, but only well insulated. 


\subsection{Particle Size Magnifier}

Particle size magnifier (PSM, Airmodus A09) used in this study is based on two recent major developments on the field of particle counting. First, on the work of Sgro and de la Mora (2004) (and the references therein) with the development of mixing type particle size magnifier for almost arbitrarily small particles, and second, on the study by lida et al. (2009) to find the most suitable working fluid to be used in a condensation particle counter (CPC). The critical dimensions and the geometry of the PSM are very close to those given by Sgro and de la Mora (2004). Diethylene-glycol was used as the working fluid. It has relatively high surface tension and low saturation vapor pressure. Because of these properties a high saturation ratio is acquired without homogeneous nucleation (Iida et al., 2009). Diethylene-glycol has also been experimentally tested in the ultrafine condensation nucleus counter (UFCNC) prototype (Stoltzenburg and McMurry, 1991) showing a superior performance in the sub$2 \mathrm{~nm}$ size range (Iida et al., 2009). Due to low vapor pressure of diethylene-glycol the particles cannot easily grow to optical sizes $(\sim 1 \mu \mathrm{m}$ in diameter). Therefore an external CPC (TSI 3010) is used for detecting the activated particles in this design. Calibration results (Vanhanen et al., 2011) have shown that PSM detects charged particles approaching efficiency of unity (practically diffusion loss limited) down to $\sim 1.5 \mathrm{~nm}$. Below that still $\sim 25 \%$ of the smallest calibration ion (tetra-methyl-ammonium-ion) with mobility equivalent diameter of $1.05 \mathrm{~nm}$, was activated in the PSM in comparison to reference electrometer (TSI 3068B). An assumption of unity detection efficiency in case of PSM is justified.

\section{Results and discussion}

Two separate experiments were conducted in the Finnish Meteorological Institute (FMI) flow tube. The nucleation rates of sulfuric acid and water were measured as a function of initial sulfuric acid concentration at three different relative humidities (16, 32 and $57 \%)$. Also the nucleation rate temperature dependency was investigated; the experiments were conducted at three temperatures $\left(25,15\right.$ and $\left.5{ }^{\circ} \mathrm{C}\right)$ while keeping the relative humidity close to $50 \%$. To obtain the initial sulfuric acid concentration, the sulfuric acid losses were estimated separately for all experimental conditions. The main reason why we focused on obtaining initial sulfuric acid concentration in our flow tube was that the concentration of prepared solution of sulfuric acid and water is known for each particular experiment and thus the initial sulfuric acid concentration determined with CIMS and IC method can be mutually compared.

\subsection{Nucleation rates}

The number concentrations of freshly nucleated particles were measured as a function of initial sulfuric acid concen- tration at several levels of relative humidities. In all experiments two different counting systems were used in parallel. An UCPC TSI 3025A which was calibrated with silver particles to a mobility diameter $\mathrm{d}_{50}$ cut-off of $2.28 \mathrm{~nm}$. The following modification to UCPC TSI 3025A has been done to obtain a $\mathrm{d}_{50}$ cut-off diameter of $2.28 \mathrm{~nm}$. The saturator temperature was increased from a nominal $37^{\circ} \mathrm{C}$ up to $38^{\circ} \mathrm{C}$, the condenser temperature was decreased from a nominal $10^{\circ} \mathrm{C}$ down to $8^{\circ} \mathrm{C}$. At these new temperatures no homogeneous nucleation was observed inside the counter. As a second counting system a mixing type particle size magnifier (PSM) with close to unity detection efficiency for mobility equivalent diameter of $1.5 \mathrm{~nm}$ was used. The initial concentration of sulfuric acid was estimated from loss measurements using CIMS and it ranged from $10^{8}$ to $3 \times 10^{9}$ molecules $\mathrm{cm}^{-3}$. The onset of nucleation for UCPC TSI 3025A particle counter was observed at sulfuric acid initial concentrations about $10^{8}$ and for PSM at about $10^{7}$ molecules $\mathrm{cm}^{-3}$ (extrapolated to $J=1 \mathrm{~cm}^{-3} \mathrm{~s}^{-1}$ ). The different counting efficiency of both counters lead to different slopes in plot of nucleation rate vs. sulfuric acid concentration. The biggest difference in counting between UCPC TSI 3025A and PSM is at lowest nucleation rates, about a factor of 200, and the smallest difference is at highest nucleation rates, about a factor of 3. From the obtained slopes it is obvious that both lines will merge at certain point, where the particle diameter of grown particles for UCPC TSI 3025A will also reach the counting efficiency of unity. The detailed comparison and explanation of differences among several counting systems can be found in Sipilä et al. (2010). The linear fits to experimental data for both particle counters are presented in Table 3. Nucleation time in our experiment is defined as time from the nucleation zone maxima to the end of the flow tube; which is half of the total residence time. Nucleation zone was determined experimentally (Brus et al., 2010) and also with Fluent CFD model (Herrmann et al., 2010), the maxima of nucleation zone was found at distance of about $1 \mathrm{~m}$ up from the nucleation chamber end. The nucleation rate is then defined as particle number concentration divided by nucleation (or half of residence) time. The highest uncertainty in nucleation rate is estimated to be factor of 2 when considering unlikely shift in position of nucleation zone maximum from $50 \mathrm{~cm}$ to $150 \mathrm{~cm}$ in the nucleation chamber. The resulting nucleation rates at relative humidities of $16,32,47$ and $57 \%$ cover about three orders of magnitude from $10^{-1}$ to $10^{2} \mathrm{~cm}^{-3} \mathrm{~s}^{-1}$ and from $10^{1}$ to $10^{4} \mathrm{~cm}^{-3} \mathrm{~s}^{-1}$ for UCPC TSI 3025A and PSM, respectively, see Fig. 1a and b. It has to be pointed out that experimental data at $\mathrm{RH}=32 \%$ were already published in Sipilä et al. (2010) and experimental data at $\mathrm{RH}=47 \%$, are taken from temperature dependency measurements (see next Sect. 3.2 Temperature dependency) to show the experiment reproducibility. 
A

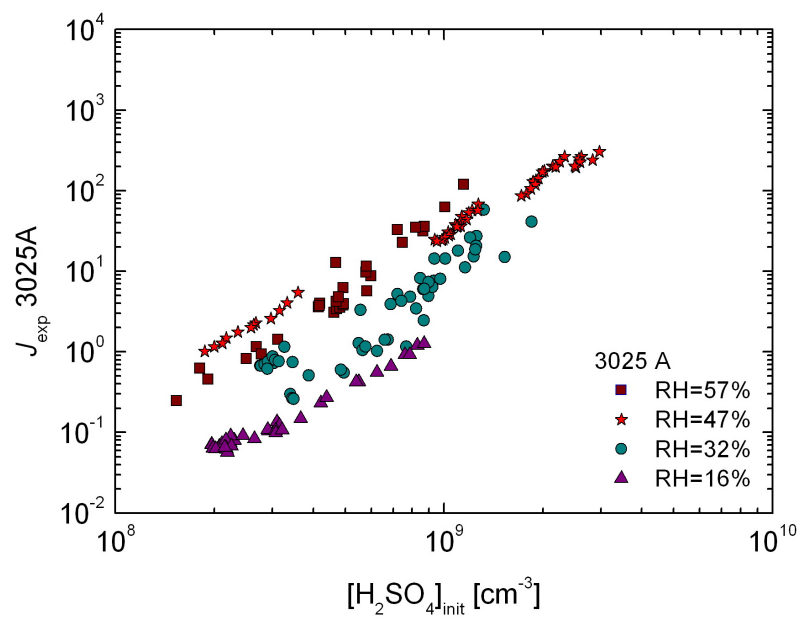

B

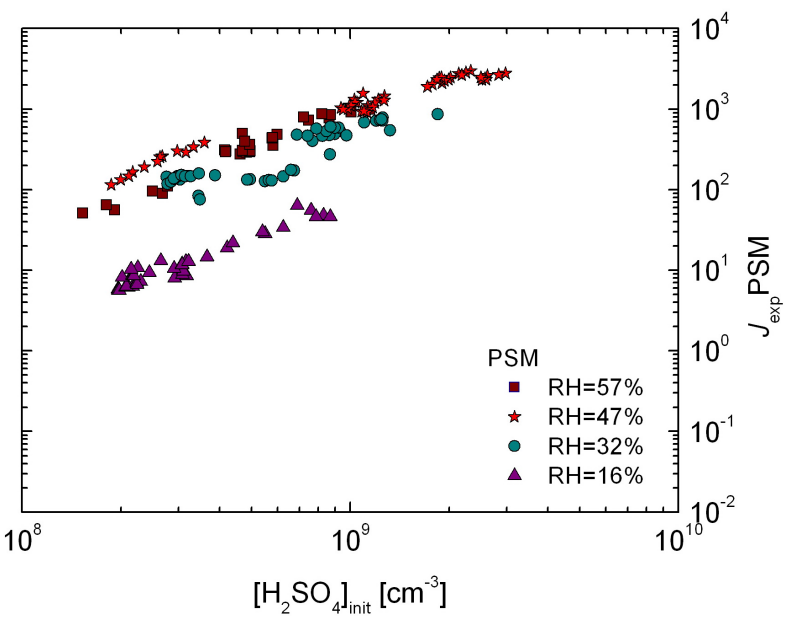

Fig. 1. Nucleation rates $\left(\mathrm{cm}^{-3} \mathrm{~s}^{-1}\right)$ of sulfuric acid and water as a function of sulfuric acid initial concentration, nucleation temperature $\mathrm{T}=25^{\circ} \mathrm{C}$. Particle number concentration measured with UCPC TSI $3025 \mathrm{~A}$ (A) and particle size magnifier (PSM) (B).

Table 3. The slopes $\left(d \ln J / d \ln \left[\mathrm{H}_{2} \mathrm{SO}_{4}\right]\right)$ of fits to data in Fig. 1. at three different relative humidities $(57,32$ and $16 \%)$, and nucleation temperature $25^{\circ} \mathrm{C}$.

\begin{tabular}{lcccc}
\hline $\begin{array}{l}\text { RH } \\
{[\%]}\end{array}$ & $\begin{array}{c}\text { slope } \\
(\mathrm{PSM})\end{array}$ & $\begin{array}{c}R^{2} \\
(\mathrm{PSM})\end{array}$ & $\begin{array}{c}\text { slope } \\
(3025 \mathrm{~A})\end{array}$ & $\begin{array}{c}R^{2} \\
(3025 \mathrm{~A})\end{array}$ \\
\hline 57 & 1.7 & 0.96 & 2.9 & 0.94 \\
32 & 1.3 & 0.75 & 2.4 & 0.83 \\
16 & 1.5 & 0.93 & 2.0 & 0.97 \\
\hline
\end{tabular}

\subsection{Temperature dependency}

The effect of temperature on nucleation rate was studied and the experimental results are presented for both counters (UCPC TSI 3025A and PSM) separately in Fig. 2a and b. The nucleation rates were measured as a function of sulfuric acid initial concentration at three temperatures 25,15 and $5{ }^{\circ} \mathrm{C}$, the relative humidity was kept close to $50 \%$. The experiment was conducted in a way that for one prepared solution of sulfuric acid and water, first all flow tube parameters ( $\mathrm{RH}, T$, total flow) were adjusted to measure nucleation temperature of $25^{\circ} \mathrm{C}$. After the experiment was finished the parameters were readjusted to measure nucleation temperature of $15^{\circ} \mathrm{C}$ by changing temperature of nucleation chamber wall and flows to keep relative humidity close to $50 \%$. Finally nucleation temperature of $5{ }^{\circ} \mathrm{C}$ was measured in the same way and the sulfuric acid - water solution was changed afterwards.

The nucleation rate shows an enhancement of more than one order of magnitude when decreasing the nucleation temperature by $20^{\circ} \mathrm{C}$ at sulfuric acid concentration of $10^{9}$ molecules $\mathrm{cm}^{-3}$ for both particle counters. At sulfuric acid concentration of $10^{8}$ molecules $\mathrm{cm}^{-3}$ the measured data show no enhancement of nucleation rate because of different slopes of isotherms. The steepest slope was observed at temperature of $5^{\circ} \mathrm{C}$ which is in disagreement with prediction of CNT (Vehkamäki et al., 2002). This might be due to undercounting of both particle counters at lower sulfuric acid concentrations. CNT predicts about $30 \%$ smaller critical cluster size at $5{ }^{\circ} \mathrm{C}$ than at $25^{\circ} \mathrm{C}$. The reduction of critical cluster size with decreasing temperature is usually also observed experimentally in unary systems (e.g. Manka et al., 2010). The experimental data for 15 and $25^{\circ} \mathrm{C}$ lie almost on top of each other; this is probably due to experimental difficulties we observed at lower temperatures 15 and $5^{\circ} \mathrm{C}$. The resulting slopes of fits to experimental data are collected in Table 4 . The temperature dependency was already studied earlier by Wyslouzil et al. (1991) in temperature range of 20$30^{\circ} \mathrm{C}$. These measurements are provided in the plot of nucleation rate vs. relative acidity, which complicates the direct comparison to our dataset, however their data indicate that a $5^{\circ} \mathrm{C}$ decrease in nucleation temperature would lead to a decrease in nucleation rate of two to four orders in magnitude.

\subsection{Dimer formation}

The formation of sulfuric acid dimer in both its hydrated and unhydrated form is the first step in sulfuric acid and water nucleation process (Hanson and Lovejoy, 2006). The working mass range of the CIMS used in this study was from $\mathrm{m} / \mathrm{z}$ channels of 40 to $250 \mathrm{Da}$, which allowed us to observe individual sulfuric molecules as $\mathrm{HSO}_{4}^{-}$at $\mathrm{m} / \mathrm{z}$ channel of $97 \mathrm{Da}$ and also sulfuric acid dimer cluster as $\mathrm{HSO}_{4}^{-} \cdot \mathrm{H}_{2} \mathrm{SO}_{4}$ at $\mathrm{m} / \mathrm{z}$ channel of $195 \mathrm{Da}$. Signal at $\mathrm{m} / \mathrm{z}$ channel of $195 \mathrm{Da}$ comprises both dimers formed inside the flow tube and the 
A

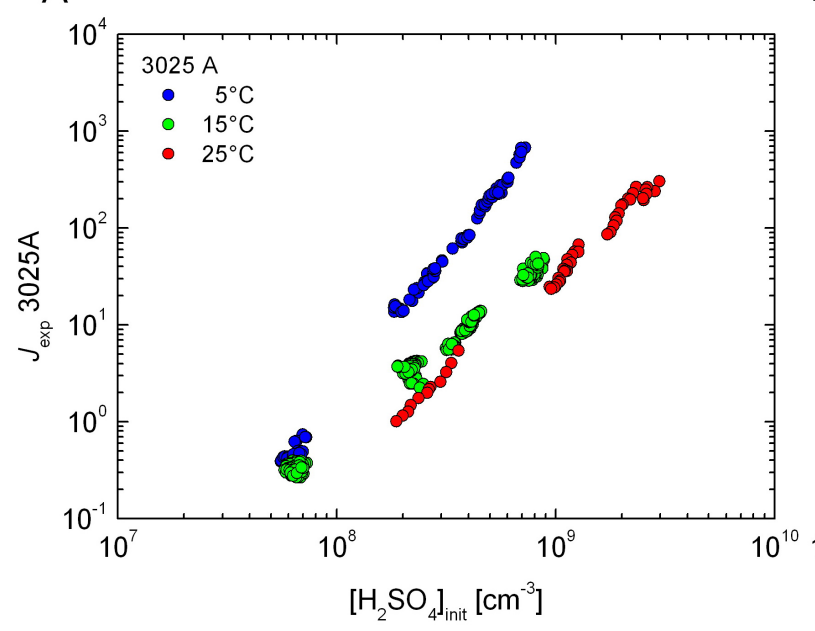

B

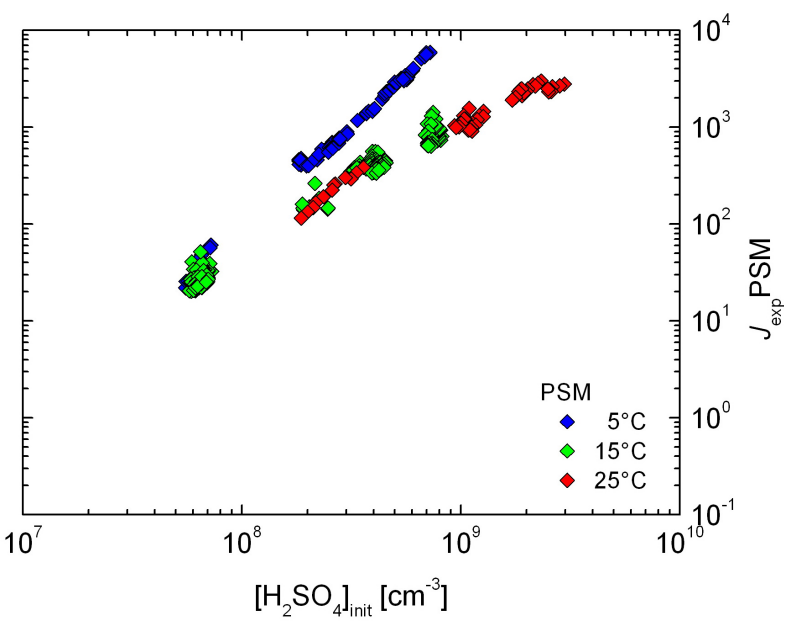

Fig. 2. Nucleation rate $\left(\mathrm{cm}^{-3} \mathrm{~s}^{-1}\right)$ as a function of sulfuric acid initial concentration at three different nucleation temperatures $(5,15$ and $25^{\circ} \mathrm{C}$ ). Particle number concentration measured with UCPC TSI 3025A (A) and particle size magnifier (PSM) (B).

Table 4. The slopes $\left(d \ln J / d \ln \left[\mathrm{H}_{2} \mathrm{SO}_{4}\right]\right)$ of fits to data in Fig. 2 at three different temperatures $\left(5,15\right.$ and $\left.25^{\circ} \mathrm{C}\right)$ and relative humidity $\sim 50 \%$.

\begin{tabular}{lcccc}
\hline $\begin{array}{l}T \\
{\left[{ }^{\circ} \mathrm{C}\right]}\end{array}$ & $\begin{array}{c}\text { slope } \\
(\mathrm{PSM})\end{array}$ & $\begin{array}{c}R^{2} \\
(\mathrm{PSM})\end{array}$ & $\begin{array}{c}\text { slope } \\
(3025 \mathrm{~A})\end{array}$ & $\begin{array}{c}R^{2} \\
(3025 \mathrm{~A})\end{array}$ \\
\hline 5 & 2.2 & 0.99 & 2.9 & 0.99 \\
15 & 1.5 & 0.99 & 1.9 & 0.99 \\
25 & 1.2 & 0.98 & 2.1 & 0.99 \\
\hline
\end{tabular}

potential contribution of ion induced clustering inside the CIMS charger. Thus, it must be pointed here that results concerning the dimer concentrations in the flow tube are still only qualitative. Generally, the observed concentration of dimer was in units of percent of the monomer concentration, which agrees with earlier studies (Eisele and Hanson, 2000). A slight RH dependency in monomer to dimer relation was observed. For the nucleation temperature of $25^{\circ} \mathrm{C}$ the increasing trend in the ratio (M/D) of monomer $(97 \mathrm{Da})$ to dimer $(195 \mathrm{Da})$ from $\sim 100$ to $\sim 200$ was observed with increasing relative humidity from 16 to $56 \%$, see Fig. 3 . The monomer to dimer ratio as a function of nucleation temperature can be seen in Fig. 4. The data are averages over whole isotherm with corresponding standard deviations as error bars. The M/D ratio is about factor of 3 larger for nucleation temperature of $25^{\circ} \mathrm{C}(\mathrm{M} / \mathrm{D}=224)$ than for $5^{\circ} \mathrm{C}$ $(\mathrm{M} / \mathrm{D}=85)$, Eisele and Hanson (2000) reported M/D value $\sim 40$ at $\sim 240 \mathrm{~K}$. The trend of M/D ratio is decreasing with decreasing temperature in our study. Similar trend was also observed in Eisele and Hanson (2000) but only for cluster bigger than trimer.

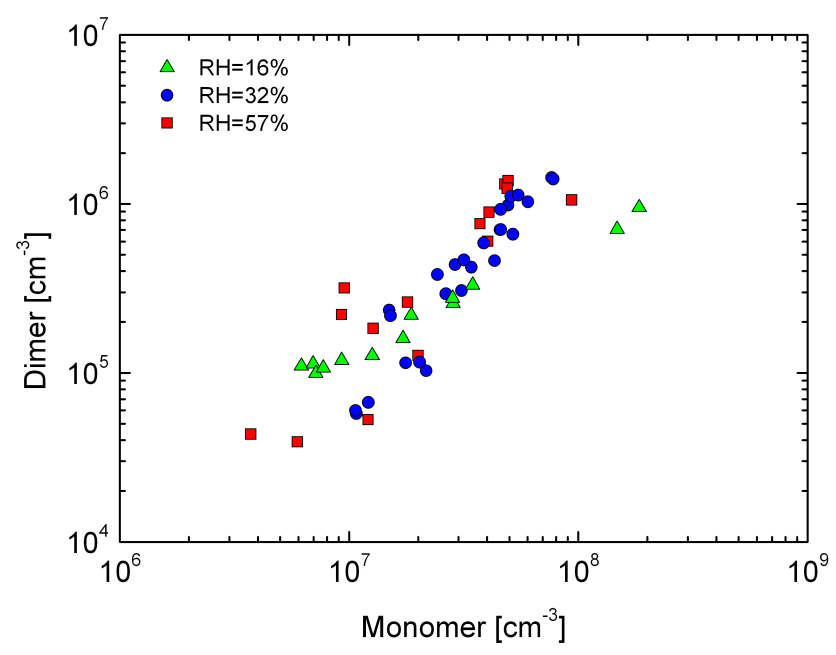

Fig. 3. Sulfuric acid dimer concentration as a function of monomer concentration at three different relative humidities and nucleation temperature $T=25^{\circ} \mathrm{C}$. The $\mathrm{M} / \mathrm{D}$ ratio is increasing from $\sim 100$ to $\sim 200$ with increasing relative humidity from 16 to $57 \%$.

\subsection{Comparison to our previous data}

The detailed comparison to other literature data concerning sulfuric acid - water system is given in our previous publication Brus et al. (2010), however the discrepancy was found in the results of this study compared to data published earlier (Brus et al., 2010). In our earlier study the method of bubblers was used to estimate concentration and the losses of sulfuric acid along the flow tube as the total sulfate $\left(\mathrm{SO}_{4}^{2-}\right)$ concentration obtained via ion chromatography (IC) analysis. In this study the initial sulfuric acid concentration measured with CIMS method reaches about $20 \%$ at $\mathrm{RH} \sim 50 \%$ 


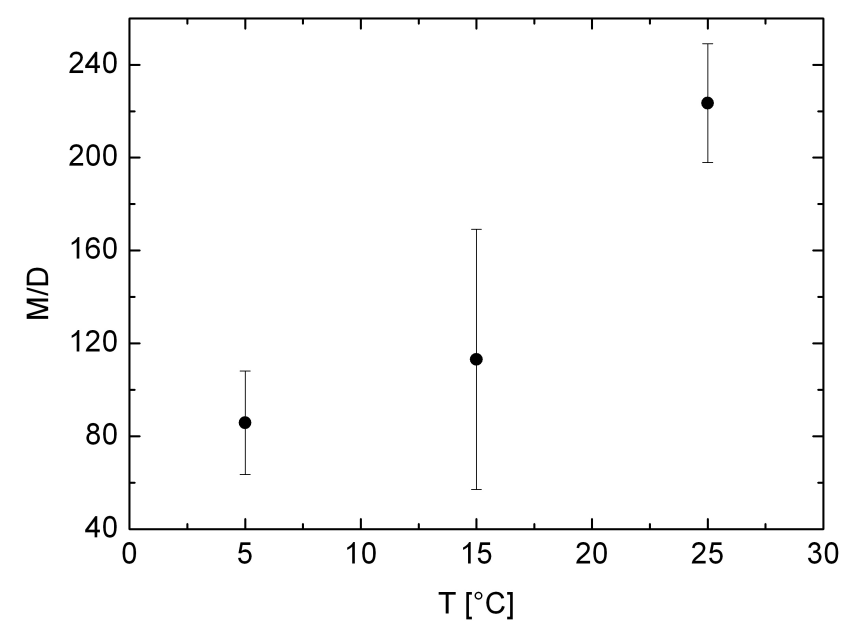

Fig. 4. Monomer to dimer ratio as a function of three different nucleation temperatures $T=5,15$ and $25^{\circ} \mathrm{C}$.

and only about $1 \%$ at RH $16 \%$ of total sulfate concentration obtained via ion chromatography (IC) analysis of the prepared liquid samples and consequent initial sulfuric acid concentration calculated by mass balance, see Fig. 5 .

There might be several reasons for such observations. The CIMS measures only monomer (97 Da) in a gas phase, the dimer concentration $(195 \mathrm{Da})$ was usually less then $1 \%$ of monomer concentration. This might indicate that the rest of sulfuric acid is in another form. The losses of sulfuric acid into particles is marginal, it was in the range of few per mille to maximum of $3 \%$ for sulfuric acid concentration range from $10^{8}$ to $10^{9}$ molecule $\mathrm{cm}^{-3}$.

What has to be also considered is shielding of sulfuric acid with water molecules. The hydration of sulfuric acid takes always place whenever traces of water are involved in the process of nucleation. According to classical theory of hydration made by Jaecker-Voirol and Mirabel (1988), JaeckerVoirol et al. (1987) and validated by Kulmala et al. (1991), only about $10 \%$ of sulfuric acid is in unhydrated form at relative humidity of $50 \%$. Salcedo et al. (2004) studied the effect of relative humidity on the detection of sulfur dioxide and sulfuric acid and found negative effect on the sensitivity of the CIMS to $\mathrm{SO}_{2}$ and $\mathrm{H}_{2} \mathrm{SO}_{4}$ because water molecules form clusters with reactant and product ions thus shielding the molecules from being ionized. They claim that the effect can be avoided by increasing the CIMS' inlet flow tube temperature to $150{ }^{\circ} \mathrm{C}$. On the other hand e.g. Eisele and Tanner (1993) in their study claim that the CIMS measurements are sensitive to total sulfuric acid without discrimination between free acid and monoacid hydrates, or even between free and higher-order acid clusters and their hydrates. Water is far more volatile than sulfuric acid and any water associated with an ion may be driven off as the ion is sampled through the collisional-dissociation chamber (CDC) of the CIMS, (Eisele and Hanson, 2000). Our results are contra in-

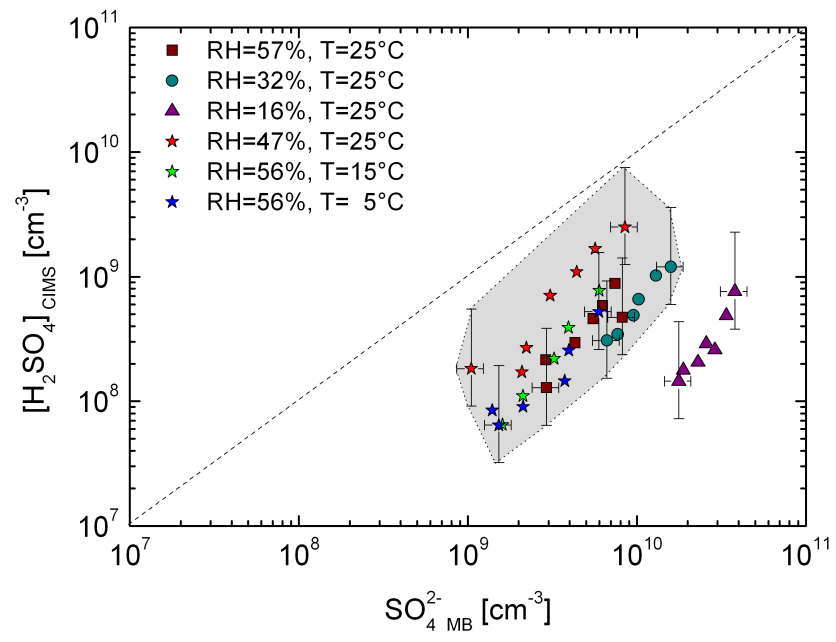

Fig. 5. The initial sulfuric acid monomer concentration determined from CIMS measurements and WLF analysis as a function of initial total sulfate concentration determined by ion chromatography (IC) analyses and subsequent mass balance calculations. The error bars stand for uncertainty in CIMS measurements (factor of two) and error propagation in total sulfate mass balance calculations $( \pm 20 \%)$.

tuitive in the case of water molecule shielding. The sulfuric acid concentration measured with CIMS is decreasing with decreasing relative humidity. If the shielding would be due to water molecules then sulfuric acid concentration would be increasing towards the lower relative humidity. Thus the shielding effect only due to water itself is an improbable explanation.

Other possibility is involvement of ammonia or other bases like amines in shielding of sulfuric acid molecules by creation of stable clusters of, in case of ammonia, ammonium sulfate or ammonium bisulfate. The discussion on the role of stabilizing compounds affecting the chemical ionization methods to determine sulfuric acid is currently ongoing (Kurtén et al., 2011). As these effects are potentially setup and instrument dependent and difficult to quantify, our concentration estimates have a larger uncertainty (factor of two) associated with them than presented earlier for the CIMS technique (30-35\%, Tanner and Eisele, 1995; Berresheim et al., 2000). Furthermore, the same calibration factor was used in converting the raw signal to monomer and dimer concentrations.

Even though the concentration of ammonia was always below the detection limit of ion chromatography (IC) analysis $\left(0.02 \mathrm{mg} \mathrm{l}^{-1}\right)$, we have no doubts that there is always certain level of ammonia present in our experiment even though the ultrapure water and particle free clean air is used. The IC ammonia detection limit $\left(0.02 \mathrm{mg} \mathrm{l}^{-1}\right)$ for our experimental setup corresponds to mixing ratio of $0.5 \mathrm{ppb}$ of ammonia, this corresponds to concentration about one order higher than sulfuric acid concentration measured with CIMS and close to ratio of unity to total sulfate concentration obtained from IC 
Table 5. Calculated median kinetic $(K)$ and activation $(A)$ coefficients at different levels of relative humidity, exponent $E$ is taken from the linear fit to PSM data of this study.

\begin{tabular}{lccc}
\hline $\begin{array}{l}\text { RH } \\
{[\%]}\end{array}$ & $\begin{array}{c}K \\
{\left[\mathrm{~cm}^{3} \mathrm{~s}^{-1}\right]}\end{array}$ & $\begin{array}{c}A \\
{\left[\mathrm{~s}^{-1}\right]}\end{array}$ & $\begin{array}{c}E \\
(\mathrm{PSM})\end{array}$ \\
\hline 57 & $1.4 \times 10^{-15}$ & $7.2 \times 10^{-7}$ & 1.7 \\
32 & $6.9 \times 10^{-16}$ & $4.9 \times 10^{-7}$ & 1.3 \\
16 & $1.3 \times 10^{-16}$ & $3.9 \times 10^{-8}$ & 1.5 \\
\hline
\end{tabular}

analysis and subsequent mass balance calculation. However ammonia was never detected in our samples, so the actual ammonia mixing ratio in our system has to be much smaller.

In this study the liquid solutions of sulfuric acid and water were prepared in the same way as in previous study (Brus et al., 2010) also the same range of total sulfate concentrations when calculated by mass balance was observed, and the similar nucleation rates when compared to UCPC 3025A were obtained for the same range of total sulfate concentration.

In conclusion, we have no certain explanation for apparent loss of sulfuric acid. Also, it should be mentioned, that Sipilä et al. (2010) also observed an apparent additional loss of molecular sulfuric acid with high initial concentrations and longer residence times. That observation was explained by rapid conversion of concentrated sulfuric acid monomer to dimer and larger clusters, stabilized by proper, possibly basic compounds (Petäjä et al., 2011). The same process can take place also in our system even though it is difficult to perceive from the data.

\subsection{Comparison to atmospheric nucleation data}

Many scientific groups found and confirmed that the vapor concentration of sulfuric acid in atmosphere is often strongly connected with new particle formation. The correlation of sulfuric acid vapor concentrations and formation rate of neutral aerosol particles can be generally expressed with two models, the kinetic model of McMurry (1980) and the activation model of Kulmala et al. (2006). Parameters of both models are determined empirically from atmospheric data. Both models are dependent on the sulfuric acid concentration, kinetic model quadratically and activation model linearly:

$J=(K$ or $A) \times\left[\mathrm{H}_{2} \mathrm{SO}_{4}\right]^{E}$,

where $K$ is a kinetic coefficient ranging from $10^{-14}$ to $10^{-11} \mathrm{~cm}^{3} \mathrm{~s}^{-1}$ and $A$ activation coefficient ranging from $10^{-7}$ to $10^{-5} \mathrm{~s}^{-1}$ (e.g. Weber et al., 1996; Sihto et al., 2006; Riipinen et al., 2007; Paasonen et al., 2010), $E$ is an exponent associated with number of sulfuric acid molecules in critical cluster (Kashchiev, 1982), it is usually found to be in between values 1 and 2 when applied to atmospheric data.
Table 6. Calculated median kinetic $(K)$ and activation $(A)$ coefficients at different nucleation temperatures, exponent $E$ is taken from the linear fit to PSM data of this study.

\begin{tabular}{lccc}
\hline $\begin{array}{l}T \\
{\left[{ }^{\circ} \mathrm{C}\right]}\end{array}$ & $\begin{array}{c}K \\
{\left[\mathrm{~cm}^{3} \mathrm{~s}^{-1}\right]}\end{array}$ & $\begin{array}{c}A \\
{\left[\mathrm{~s}^{-1}\right]}\end{array}$ & $\begin{array}{c}E \\
(\mathrm{PSM})\end{array}$ \\
\hline 5 & $1.0 \times 10^{-14}$ & $1.0 \times 10^{-6}$ & 2.2 \\
15 & $3.6 \times 10^{-15}$ & $8.5 \times 10^{-7}$ & 1.5 \\
25 & $8.0 \times 10^{-16}$ & $2.6 \times 10^{-6}$ & 1.2 \\
\hline
\end{tabular}

In this study we compare our experimental data to latest atmospheric data analysis made by Paasonen et al. (2010) where two CIMS systems were used at four measurement sites - Hyytiälä (Finland), Hohenpeissenberg and Melpitz (Germany), and San Pietro Capofiume (Italy). The measurements in Hohenpeissenberg, Melpitz and San Pietro Capofiume were performed with the CIMS of German Weather Service (DWD), whereas in Hyytiälä the CIMS of the University of Helsinki (UHEL) was used. The two instruments are very similar, as the UHEL CIMS is built at the National Center for Atmospheric Research (NCAR, USA), and also the DWD CIMS is NCAR-type CIMS. They also rely on the same calibration procedure, for more details see Paasonen et al. (2010). However, as Paasonen et al. (2010) concluded, the nucleation rates in Hohenpeissenberg were not closely connected to sulfuric acid concentration, and thus our comparison is made only to the data from the other three sites, see Fig. 6. The formation rates of $2 \mathrm{~nm}$ neutral particles $\left(J_{2}\right)$ were obtained at all stations from particle size distributions recorded on nucleation event days. Such dataset can be directly compared to nucleation rates obtained with PSM in our study. The exponents from linear fits to our experimental data range from 1.2 to 2.2 , depending on relative humidity and nucleation temperature. The worse agreement between our experiment and atmospheric data was found for the highest nucleation temperature $\left(25^{\circ} \mathrm{C}\right)$ and the lowest relative humidity (RH $16 \%$ ), see Fig. 6. The kinetic and activation coefficients obtained from our experimental data are in close agreement to atmospheric ones even though the range of relative humidities and temperatures of atmospheric data is quite wide, see Tables 5 and 6 . The median kinetic and activation coefficients of whole dataset presented in Paasonen et al. (2010) (Table 4 therein) are $K=26 \times 10^{-14} \mathrm{~cm}^{3} \mathrm{~s}^{-1}$ and $A=9.7 \times 10^{-7} \mathrm{~s}^{-1}$. In our study we found median coefficients for whole dataset to be $K=0.1 \times 10^{-14} \mathrm{~cm}^{3} \mathrm{~s}^{-1}$ and $A=7.85 \times 10^{-7} \mathrm{~s}^{-1}$, thus favouring the activation mechanism in nucleation process. However, this kind of interpretation has to be considered with cautiousness, because the nucleation coefficients may be strongly dependent on some other quantities, e.g. low-volatility organic vapor concentration as suggested by Paasonen et al. (2010). 


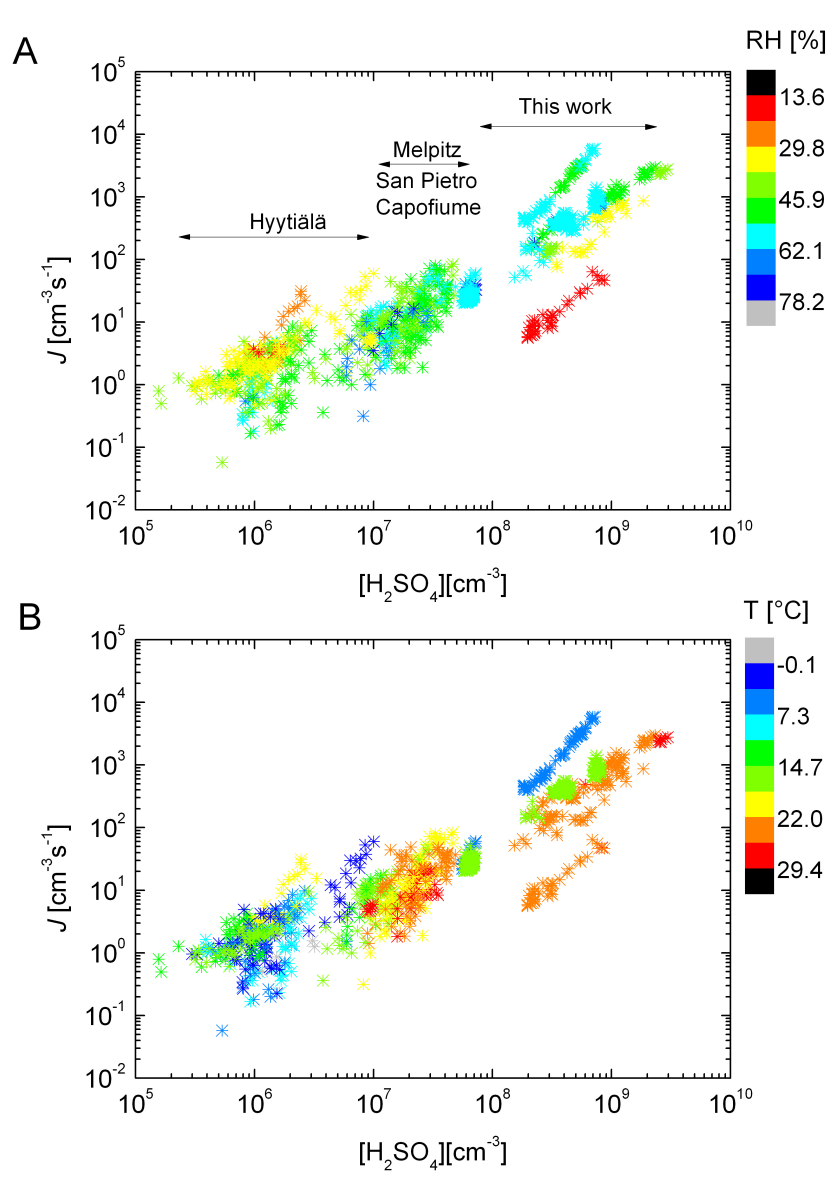

Fig. 6. Nucleation rates as a function of sulfuric acid concentration, comparison of atmospheric data (Paasonen et al., 2010) and this study according to relative humidity (A) and temperature (B).

\section{Conclusions}

In this study the homogeneous nucleation rates of sulfuric acid and water were measured in two separate sets of experiment. In first one we tested the influence of relative humidity in the range from 16 to $57 \%$ and in second one the influence of temperature on nucleation rate at three different nucleation temperatures 25,15 and $5{ }^{\circ} \mathrm{C}$. Two condensation particle counters (UCPC TSI 3025A and PSM with CPC TSI 3010) with different $d_{50}$ detection efficiency were used in parallel to count freshly nucleated particles. The gas phase sulfuric acid concetration was measured with CIMS. The initial concentration of sulfuric acid was estimated from loss measurements using CIMS and it ranged from $10^{8}$ to $3 \times 10^{9}$ molecules $\mathrm{cm}^{-3}$. The losses of sulfuric acid along the flow tube were estimated for each particular set of experimental conditions. The onset of nucleation for UCPC TSI 3025A was observed at sulfuric acid initial concentrations at about $10^{8}$ and for PSM at about $10^{7}$ molecules $\mathrm{cm}^{-3}$. The resulting nucleation rates at relative humidities of 16, 32, 47 and $57 \%$ cover about three orders of magnitude from $10^{-1}$ to $10^{2}$ and from $10^{1}$ to $10^{4}$ for UCPC TSI 3025A and PSM, respectively. The nucleation rate shows an enhancement of more than one order of magnitude per decreasing the nucleation temperature by $20^{\circ} \mathrm{C}$ at sulfuric acid concentration of $10^{9}$ molecules $\mathrm{cm}^{-3}$ for both particle counters. At sulfuric acid concentration of $10^{8}$ molecules $\mathrm{cm}^{-3}$ the measured data show no enhancement of nucleation rate because of different slopes of isotherms. The concentration of dimers was found to be usually less than one percent of monomer concentration. Obtained experimental nucleation rate data were also compared to two empirical (kinetic and activation) models. The obtained median activation coefficients are close to the atmospheric ones, whereas the kinetic coefficients were from one to three orders of magnitude smaller. However it has to be pointed out that these coefficients may be strongly dependent on some other quantities like low-volatility organic vapor concentration. The exponents obtained from fits to our data are in the range of 1.2 to 2.2 , depending on relative humidity and nucleation temperature. Even though the sulfuric acid concentration determined together from CIMS measurements and wall loss estimates was only $10 \%$ of the total sulfate concentration obtained via Ion Chromatography analysis and subsequent mass balance (Brus et al., 2010), the slopes in figures $J$ vs. $\left[\mathrm{H}_{2} \mathrm{SO}_{4}\right]$ and $J$ vs. total sulfate are the same. This probably means that the form and amount of active sulfuric acid involved in nucleation process itself is ambiguous and it is limited from left side by free $\left[\mathrm{H}_{2} \mathrm{SO}_{4}\right]$ and from right side by total sulfate concentration. The participation of ammonia can not be disproved in our nucleation experiment, even though the concentration of ammonia never reached the detection limit of IC analysis.

Acknowledgements. Authors would like to acknowledge KONE foundation, Maj \& Tor Nessling foundation, EUCAARI project (The European Integrated project on Aerosol Cloud Climate and Air Quality Interactions) and FCoE (Finnish Center of Excellence of Academy of Finland, project no. 1118615) for their financial support.

Edited by: A. Wiedensohler

\section{References}

Ball, S. M., Hanson, D. R., Eisele, F. L., and McMurry, P. H.: Laboratory studies of particle nucleation: Initial results for $\mathrm{H}_{2} \mathrm{SO}_{4}$, $\mathrm{H}_{2} \mathrm{O}$, and $\mathrm{NH}_{3}$ vapors., J. Geophys. Res., 104(D19), 2370923718, 1999.

Benson, D. R., Young, L. H., Kameel, F. R., and Lee, S.-H.: Laboratory-measured nucleation rates of sulfuric acid and water binary homogeneous nucleation from the $\mathrm{SO}_{2}+\mathrm{OH}$ reaction, Geophys. Res. Lett., 35, L11801, doi:10.1029/2008GL033387, 2008.

Berndt, T., Böge, O., Stratmann, F., Heintzenberg, J., and Kulmala, M.: Rapid formation of sulfuric acid particles at near atmospheric conditions, Science, 307, 698-700, 2005. 
Berndt, T., Stratmann, F., Sipilä, M., Vanhanen, J., Petäjä, T., Mikkilä, J., Grüner, A., Spindler, G., Lee Mauldin III, R., Curtius, J., Kulmala, M., and Heintzenberg, J.: Laboratory study on new particle formation from the reaction $\mathrm{OH}+\mathrm{SO}_{2}$ : influence of experimental conditions, $\mathrm{H}_{2} \mathrm{O}$ vapour, $\mathrm{NH}_{3}$ and the amine tert-butylamine on the overall process, Atmos. Chem. Phys., 10, 7101-7116, doi:10.5194/acp-10-7101-2010, 2010.

Berresheim, H., Elste, T., Plass-Dülmer, C., Eisele, F. L., and Tanner, D. J.: Chemical ionization mass spectrometer for longterm measurements of atmospheric $\mathrm{OH}$ and $\mathrm{H}_{2} \mathrm{SO}_{4}$, Int. J. Mass. Spec., 202, 91-109, 2000.

Brus, D., Hyvärinen, A.-P., Viisanen, Y., Kulmala, M., and Lihavainen, H.: Homogeneous nucleation of sulfuric acid and water mixture: experimental setup and first results, Atmos. Chem. Phys., 10, 2631-2641, doi:10.5194/acp-10-2631-2010, 2010.

Eisele, F. L. and Hanson, D. R: First measurements of prenucleation molecular clusters, J. Phys. Chem. A, 104, 830-836, 2000.

Eisele, F. L. and Tanner, D.: Measurement of the gas phase concentration of $\mathrm{H}_{2} \mathrm{SO}_{4}$ and methane sulfonic acid and estimates of $\mathrm{H}_{2} \mathrm{SO}_{4}$ production and loss in the atmosphere, J. Geophys. Res., 98, 9001-9010, 1993.

Hanson, D. R. and Eisele, F. L.: Diffusion of $\mathrm{H}_{2} \mathrm{SO}_{4}$ in humidified nitrogen: Hydrated $\mathrm{H}_{2} \mathrm{SO}_{4}$, J. Phys. Chem. A, 104, 1715-1719, 2000.

Hanson, D. R. and Lovejoy, E. R.: Measurements of the thermodynamics of the hydrated dimmer and trimer of sulfuric acid, J. Phys. Chem. A, 110(31), 9525-9527, 2006.

Herrmann, E., Brus, D., Hyvärinen, A.-P., Stratmann, F., Wilck, M., Lihavainen, H., and Kulmala, M.: A computational fluid dynamics approach to nucleation in the water-sulfuric acid -system, J. Phys. Chem. A, 114(31), 8033-8042, 2010.

Iida, K., Stolzenburg, M., and McMurry, P. H.: Effect of Working Fluid on Sub-2 nm Particle Detection with a Laminar Flow Ultrafine Condensation Particle Counter, Aerosol Sci. Technol., 43, 81-96, 2009.

Jaecker-Voirol, A. and Mirabel, P.: Nucleation rate in a binary mixture of sulfuric acid and water vapor, J. Phys. Chem., 92(12), 3518-3521, 1988.

Jaecker-Voirol, A., Mirabel, P., and Reiss, H.: Hydrates in supersaturated binary sulphuric acid-water vapor: A reexamination, J. Chem. Phys., 87, 4849-4852, 1987.

Kashchiev, D.: On the relation between nucleation work, nucleus size and nucleation rate, J. Chem. Phys., 76, 5098-5102, 1982.

Kulmala, M.: How particles nucleate and grow, Science, 302, 10001001, 2003.

Kulmala, M., Lazaridis, M., Laaksonen, A., and Vesala, T.: Extended hydrates interaction model: Hydrate formation and the energetics of binary homogeneous nucleation, J. Chem. Phys. 94(11), 7411-7413, 1991.

Kulmala, M., Lehtinen, K. E. J., and Laaksonen, A.: Cluster activation theory as an explanation of the linear dependence between formation rate of $3 \mathrm{~nm}$ particles and sulphuric acid concentration, Atmos. Chem. Phys., 6, 787-793, doi:10.5194/acp-6-787-2006, 2006.

Kurtén, T., Petäjä, T., Smith, J., Ortega, I. K., Sipilä, M., Junninen, H., Ehn, M., Vehkamäki, H., Mauldin, L., Worsnop, D. R., and Kulmala, M.: The effect of $\mathrm{H}_{2} \mathrm{SO}_{4}$ - amine clustering on chemical ionization mass spectrometry (CIMS) measurements of gas-phase sulfuric acid, Atmos. Chem. Phys., 11, 3007-3019, doi:10.5194/acp-11-3007-2011, 2011.

Manka, A. A., Brus, D., Hyvärinen, A.-P., Lihavainen, H., Wolk, J., and Strey, R.: Homogeneous water nucleation in a laminar flow diffusion chamber, J. Chem. Phys. 132, 244505, doi:10.1063/1.3427537, 2010.

Mauldin III, R. L., Frost, G., Chen, G., Tanner, D., Prevot, A., Davis, D., and Eisele, F.: $\mathrm{OH}$ measurements during the First Aerosol Characterization Experiment (ACE 1): Observations and model comparisons, J. Geophys. Res., 103, 16713-16729, 1998.

McMurry, P. H.: Photochemical Aerosol Formation from $\mathrm{SO}_{2}$ : A Theoretical Analysis of Smog Chamber Data, J. Colloid Interface Sci. 78, 513-527, 1980.

Metzger, A., Verheggen, B., Dommen, J., Duplissy, J., Prevot, A. S., Weingartner, E., Riipinen, I., Kulmala, M., Spracklen, D. V., Carslaw, K. S., and Baltensperger, U.: Evidence for the role of organics in aerosol particle formation under atmospheric conditions, P. Natl. Acad. Sci., 107, 6646-6651, doi:10.1073/pnas.0911330107, 2010.

Paasonen, P., Nieminen, T., Asmi, E., Manninen, H. E., Petäjä, T., Plass-Dülmer, C., Flentje, H., Birmili, W., Wiedensohler, A., Hõrrak, U., Metzger, A., Hamed, A., Laaksonen, A., Facchini, M. C., Kerminen, V.-M., and Kulmala, M.: On the roles of sulphuric acid and low-volatility organic vapours in the initial steps of atmospheric new particle formation, Atmos. Chem. Phys., 10, 11223-11242, doi:10.5194/acp-10-11223-2010, 2010.

Petäjä, T., Mauldin, III, R. L., Kosciuch, E., McGrath, J., Nieminen, T., Paasonen, P., Boy, M., Adamov, A., Kotiaho, T., and Kulmala, M.: Sulfuric acid and $\mathrm{OH}$ concentrations in a boreal forest site, Atmos. Chem. Phys., 9, 7435-7448, doi:10.5194/acp9-7435-2009, 2009.

Petäjä, T., Sipilä, M., Paasonen, P., Nieminen, T., Kurtén, T., Ortega, I. K., Stratmann, F., Vehkamäki, H., Berndt, T., and Kulmala, M.: Experimental Observation of Strongly Bound Dimers of Sulfuric Acid: Application to Nucleation in the Atmosphere, Phys. Rev. Lett., 106, 228302 , doi:10.1103/PhysRevLett.106.228302, 2011.

Riipinen, I., Sihto, S.-L., Kulmala, M., Arnold, F., Dal Maso, M., Birmili, W., Saarnio, K., Teinilä, K., Kerminen, V.-M., Laaksonen, A., and Lehtinen, K. E. J.: Connections between atmospheric sulphuric acid and new particle formation during QUEST IIIIV campaigns in Heidelberg and Hyytiälä, Atmos. Chem. Phys., 7, 1899-1914, doi:10.5194/acp-7-1899-2007, 2007.

Salcedo, D., Villalta, P. W., Varutbangkul, V. Wormhoundt, J. C. , Miake-Lye, R. C., Worsnop, D. R., Ballenthin, J. O., Thorn, W. F., Viggiano, A. A., Miller, T. M., Flagan, R. C., and Seinfeld, J. H.: Effect of relative humidity on the detection of sulfur dioxide and sulfuric acid using a chemical ionization mass spectrometer, Int. J. Mass. Spectrom., 231, 17-30, 2004.

Sihto, S.-L., Kulmala, M., Kerminen, V.-M., Dal Maso, M., Petäjä, T., Riipinen, I., Korhonen, H., Arnold, F., Janson, R., Boy, M., Laaksonen, A., and Lehtinen, K. E. J.: Atmospheric sulphuric acid and aerosol formation: implications from atmospheric measurements for nucleation and early growth mechanisms, Atmos. Chem. Phys., 6, 4079-4091, doi:10.5194/acp-6-4079-2006, 2006.

Sipilä, M. Berndt, T., Petäjä, T., Brus, D., Vanhanen, J., Stratmann, F., Patokoski, J., Mauldin III, R. L., Hyvärinen, A.P., Lihavainen, H., and Kulmala, M.: The role of sulfuric 
acid in atmospheric nucleation, Science, 327(5970), 1243-1246, doi:10.1126/science.1180315, 2010.

Sgro, L. A. and de la Mora, J. F.: A simple turbulent mixing CNC for charged particle detection down to $1.2 \mathrm{~nm}$, Aerosol. Sci. Technol., 38, 1-11, 2004.

Stoltzenburg, M. R. and McMurry, P. H.: An ultrafine aerosol condensation nucleus counter, Aerosol Sci. Technol. 14, 48-65, 1991.

Tanner, D. J. and Eisele, F. L.: Present OH measurement limits and associated uncertainties, J. Geophys. Res., 100(D2), 2883-2892, doi:10.1029/94JD02609, 1995.

Vanhanen, J., Mikkilä, J., Sipilä, M., Manninen, H. E., Lehtipalo, K., Siivola, E., Petäjä, T., and Kulmala, M.: Particle size magnifier for nano-CN detection, Aerosol Sci. Technol. 45, 533-542, 2011.

Vehkamäki, H., Kulmala, M., Napari, I., Lehtinen, K. E. J., Timmreck, C., Noppel M., and Laaksonen, A.: An improved parameterization for sulfuric acid-water nucleation rates for tropospheric and stratospheric conditions, J. Geophys. Res., 107(D22), 4622, doi:10.1029/2002JD002184, 2002.

Weber, R. J., Marti, J., McMurry, P. H., Eisele, F., Tanner, D. J., and Jefferson, A.: Measured atmospheric new particle formation rates: implications for nucleation mechanisms, Chem. Eng. Commun., 151, 53-64, 1996.

Weber, R. J., Marti, J. J., McMurry, P. H., Eisele, F. L., Tanner, D. J., and Jefferson, A.: Measurements of new particle formation and ultrafine particle growth rates at a clean continental site, J. Geophys. Res., 102, 4373-4385, 1997.
Wyslouzil, B. E., Sienfeld, J. H., Flagan, R. C., and Okuyama, K.: Binary nucleation in acid-water systems. II. Sulphuric acid-water and a comparison with methanesulphonic acid-water, J. Chem. Phys., 94, 6842-6850, 1991.

Young, L. H., Benson, D. R., Kameel, F. R., Pierce, J. R., Junninen, H., Kulmala, M., and Lee, S.-H.: Laboratory studies of $\mathrm{H}_{2} \mathrm{SO}_{4} / \mathrm{H}_{2} \mathrm{O}$ binary homogeneous nucleation from the $\mathrm{SO}_{2}+\mathrm{OH}$ reaction: evaluation of the experimental setup and preliminary results, Atmos. Chem. Phys., 8, 4997-5016, doi:10.5194/acp-84997-2008, 2008.

Zhang, R.: Getting to the Critical Nucleus of Aerosol Formation, Science, 328(5984), 1366-1367, doi:10.1126/science.1189732, 2010.

Zhang, R., Suh, I., Zhao, J., Zhang, D., Fortner, E. C., Tie, X., Molina, L. T., and Molina, M. J.: Atmospheric new particle formation enhanced by organic acids, Science, 304(5676), 14871490, doi:10.1126/science.1095139, 2004.

Zhao, J., Eisele, F. L., Titcombe, M., Kuang, C., and McMurry, P. H.: Chemical ionization mass spectrometric measurements of atmospheric neutral clusters using the cluster-CIMS, J. Geophys. Res., 115, D08205, doi:10.1029/2009JD012606, 2010. 